Disponível em

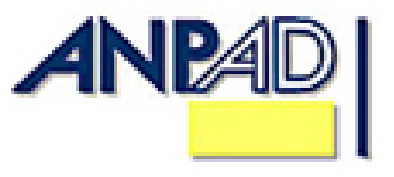

http://www.anpad.org.br/rac

RAC, Rio de Janeiro, v. 16, n. 1, art. 1,

pp. 1-22, Jan./Fev. 2012

$(\infty)$ EY-No

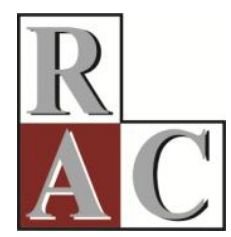

\title{
Decisões de Investimento em Ativos de Longo Prazo nas Empresas Brasileiras: Qual a Aderência ao Modelo Teórico? ${ }^{(1)}$
}

\section{Brazilian Companies' Investment Decisions Concerning Long-term Assets: How Do They Adhere to the Theoretical Model?}

\author{
Fábio Frezatti * \\ E-mail: frezatti@usp.br \\ Universidade de São Paulo - FEA/USP \\ São Paulo, SP, Brasil. \\ Diógenes de Souza Bido \\ E-mail: diogenesbido@yahoo.com.br \\ Universidade Presbiteriana Mackenzie \\ São Paulo, SP, Brasil. \\ Ana Paula Capuano da Cruz \\ E-mail: anapaulacapuanocruz@ hotmail.com \\ Universidade Federal do Pampa - UNIPAMPA \\ Santana do Livramento, RS, Brasil. \\ Marcelo Francini Girão Barroso \\ E-mail: marcelobarroso@usp.br \\ Universidade de São Paulo - FEA/USP \\ São Paulo, SP, Brasil. \\ Maria José de Camargo Machado \\ E-mail: mjzen@terra.com.br \\ Universidade Metodista de Piracicaba - UNIMEP \\ Piracicaba, SP, Brasil.
}

* Endereço: Fábio Frezatti

Av. Prof. Luciano Gualberto, 908, FEA 3, sala 226, Cidade Universitária, São Paulo/SP, 05508-900.

Copyright (C) 2012 RAC. Todos os direitos, até mesmo de tradução, são reservados. É permitido citar parte de artigos sem autorização prévia, desde que seja identificada a fonte. 


\title{
Resumo
}

O objetivo deste estudo foi verificar como as organizações brasileiras de grande porte tratam investimentos de longo prazo. O constructo teórico levou em conta tanto a literatura de estratégia quanto a de finanças, a partir das quais foram propostas hipóteses envolvendo a utilização de métodos e mecanismos para avaliação de investimentos. Por meio de um questionário eletrônico, desenvolveu-se um levantamento junto a 82 empresas, e, com o emprego da técnica de modelagem de equações estruturais, constatou-se aderência parcial ao modelo teórico. Dentre os achados, verificou-se que os mecanismos de análise de investimentos estão associados positivamente à preocupação com a análise do risco percebido. Em adição, constatou-se que projetos aprovados no planejamento estratégico apresentam acompanhamento relativamente mais estruturado e que a maior necessidade de definição de financiamento e custo de oportunidade está associada positivamente à inclusão do projeto no planejamento estratégico.

Palavras-chave: decisões de investimentos; ativos de longo prazo; acompanhamento de projetos; avaliação de investimentos.

\begin{abstract}
This study sought to determine how large Brazilian organizations treat long-term investments. The theoretical construct took into account literature from the fields of strategy and finance, both of which offer hypotheses that use methods and mechanisms in order to evaluate investments. Using an online questionnaire, a survey including 82 companies was developed. Utilizing structural equation modeling, partial adherence to the theoretical model was found. It was found that the mechanisms of investment analysis are positively associated with concern about the perceived risk analysis. In addition, it was discovered that projects approved through strategic planning have relatively more structured monitoring; and also that a greater need for defining funding and opportunity costs is positively associated with a project's inclusion in strategic planning.
\end{abstract}

Key words: investment decisions; long-term assets; project monitoring; investment evaluation. 


\section{Introdução}

Decisões de investimentos são estruturadoras dos ativos de uma organização, sendo o conjunto de elementos gerador de benefícios futuros aos agentes envolvidos. Decisões desse tipo, especialmente as que visam a alcançar benefícios em longo prazo, carecem de análises que considerem ponderadamente o risco inerente à decisão, a necessidade de financiamento também a longo prazo, a possível exigência de processo decisório integrado na visão de longo prazo, o envolvimento de níveis hierárquicos distintos no processo decisório e a vida útil dos ativos. Assim, tais decisões integram o processo de planejamento empresarial, tanto no âmbito estratégico quanto orçamentário.

Dessa maneira, verifica-se que decisões que envolvem investimentos de longo prazo demandam cuidadosas avaliações de elementos que afetam a perspectiva de retorno e a sustentabilidade da organização no longo prazo, devendo ser tratadas de maneira priorizada, estruturada e consistente com suas demandas. No entender de Slagmulder (1997), o processo estruturado de análise de investimentos de longo prazo demanda um conjunto de instrumentos relacionado com o sistema de controle gerencial das organizações.

Considerando que as respostas para essas demandas requerem certo grau de maturidade gerencial da organização, ou seja, uma espécie de mescla peculiar que deveria articular análise estratégica e financeira (Alkaraan \& Northcott, 2006), a questão desta pesquisa é: como as organizações brasileiras tratam os investimentos de longo prazo?

A proposta consiste em verificar se há encaixe entre o modelo estruturado de análise de investimentos e as práticas dessa natureza adotadas por empresas brasileiras de grande porte. Assim, espera-se contribuir para identificação e compreensão dos fatores que orientam a tomada de decisão e de controle do modelo estruturado de análise de investimentos, sobretudo porque pouco se sabe, empiricamente, sobre os aspectos explorados para decisões de investimentos (Alkaraan \& Northcott, 2007). Além disso, ressalta-se que o presente estudo ocupa-se do resgate de problemas que têm relevância prática no escopo do Sistema de Informações Gerenciais e se propõe a gerar um produto que pode contribuir para identificação de pontos fortes e fracos do gerenciamento que vem sendo praticado, e, dessa forma, orientando a ação empresarial.

Complementarmente a essa introdução, este trabalho está estruturado em mais cinco seções. A segunda contém o quadro teórico de referência que respalda a investigação. Na sequência, a terceira seção destina-se à exposição do modelo teórico e das hipóteses formuladas para pesquisa. Os procedimentos metodológicos estão descritos na quarta seção. Dando seguimento, a quinta seção reúne a análise e a discussão dos resultados, e, por fim, na sexta seção, têm-se as conclusões da investigação.

\section{Revisão da Literatura}

Nesta seção são explicitados os seguintes elementos: (a) conceitos de ativos de longo prazo e de investimentos estratégicos relevantes para estabelecer o foco de análise da pesquisa; (b) instrumentos formais de planejamento necessários para entender como a decisão de investimentos ocorre e em que dimensão e hierarquia; (c) financiamento de longo prazo (variável intimamente ligada à decisão de investimento); (d) percepção de risco, elemento intrínseco ao processo decisório; e, (e) métodos de análise de investimentos e mecanismos adicionais.

\section{Conceito de ativos de longo prazo e investimentos estratégicos}

Ativos são "recursos controlados pela entidade como resultado de eventos passados e dos quais benefícios econômicos futuros são esperados que fluam à entidade" (International Accounting Standards Board [IASB], 1989, p. A40). Por benefícios econômicos futuros, compreende-se "o 
potencial para contribuir, direta ou indiretamente, ao fluxo de caixa ou de equivalentes-caixa à entidade" (IASB, 1989, p. A41), seja na forma de potencial produtivo, de conversibilidade em caixa ou equivalentes-caixa ou de capacidade para redução de saídas de caixa. Ativos de longo prazo (LP) intangíveis, imobilizados e investimentos de longo prazo em outras sociedades (Haka, 2007) enquadram-se nesta caracterização. Por terem sua maturação no longo prazo, os ativos dessa natureza apresentam implicações de risco e de retorno distintas dos demais ativos. Assim, visando à obtenção de retorno, o horizonte de vida útil dos ativos deve ser igual ou superior ao prazo em que geram o retorno. Ainda, estes investimentos são de difícil quantificação quanto à totalidade do benefício esperado e impactam consideravelmente o desempenho corporativo ao longo prazo (Alkaraan \& Northcott, 2007).

Não obstante técnicas diversas para análise e avaliação de projetos de investimento de longo prazo, outros fatores podem afetar a decisão de gestores sobre eles. Argumenta-se que a pressão pela aquisição do controle da firma seria prejudicial a ela, pois induziria gestores a sacrificar resultados de longo prazo na tentativa de aumentar resultados presentes (Shleifer \& Vishny, 1986; Stein, 1988). Israel e Ma (1999), por sua vez, concluem que pressão por aquisição de controle, ao contrário, incentiva investimentos em projetos de longo prazo. Conforme argumentado pelos autores, "ineficiência de investimentos sob pressão de aquisição é mais provável na forma de sobreinvestimento em projetos de longo prazo do que na forma de sobre-investimento em projetos de curto prazo" (Israel \& Ma, 1999, p. 3).

Investimentos em ativos de longo prazo podem ser divididos em estratégicos e não-estratégicos (Slagmulder, 1997). Embora esse aspecto seja relevante, existe certa dificuldade de se caracterizar, de forma generalizada, o investimento estratégico. Podem ser caracterizados estratégicos, conforme uma definição de investimentos que ajudam a organização a atingir seus objetivos de longo prazo e que sustentam sua posição competitiva no mercado (Butler, Davies, Pike, \& Sharp, 1991; Marsh, Barwise, Thomas, \& Wensley, 1988). Slagmulder (1997) e Haka (2007), entretanto, criticam o foco que conduz mais a discussão para sua ligação com os planos formais da organização do que propriamente às estratégias desta, o que deixa de atender à perspectiva apregoada por Simons (1995). Este autor destaca a necessidade de considerar o processo de planejamento tanto no sistema de controle diagnóstico (aquele que permite o acompanhamento) como no sistema de controle interativo (que fornece uma visão mais dinâmica, relacionada com o todo e voltada para estratégias emergentes que demandam prospecção de novas oportunidades). Dada a controvérsia, a relevância dos investimentos passa a ser contextual, decorrendo da maneira como são especificamente entendidos em termos de impacto no negócio.

\section{Instrumentos formais de planejamento}

A abordagem da teoria da agência (Jensen \& Meckling, 1976) demanda uma estrutura para que o convívio entre o sócio e o gestor ocorra no horizonte de LP. Essa perspectiva identifica o processo de planejamento estruturado, contendo o planejamento estratégico e o orçamento desenvolvidos da maneira como a entidade o desejar. Quanto aos investimentos, uma estrutura de métodos de avaliação e mecanismos de análise de risco deve ser considerada. Isso porque, conforme Slagmulder (1997), investimentos de capital são vitais à promulgação da estratégia das organizações, uma vez que solidificam as bases de seus processos de criação de valor. Segundo o autor, decisões de investimentos estratégicos, normalmente, envolvem um volume expressivo de recursos e têm impacto significativo na posição competitiva da empresa e no seu desempenho futuro, e, por este motivo, devem ser efetivamente controladas.

A literatura é muito fragmentada ao tratar a associação da discussão estratégica com a financeira, requerendo a identificação de autores/teorias que possam conversar sobre planejamento. A rigor, a literatura de finanças não se preocupa em tratar o processo de planejamento. Em alguns casos, indica a existência da estratégia ou mesmo do capital budgeting, mas não necessariamente dentro de um instrumento mais amplo de planejamento formal, embora seja citado o sistema estratégico de 
investimentos, sugerindo algo com autonomia (Carr \& Tomkins, 1998; Carr, Kolehmainen, \& Mitchell, 2010).

Para as finalidades deste artigo, o mais relevante em termos de investimento consiste em identificar e criar vantagens competitivas no mercado, decorrentes da estratégia corporativa da organização, o que representa uma abordagem qualitativa para o assunto. Na visão de Shapiro (1998), por exemplo, admite-se que a aceitação de projetos esteja unicamente fundamentada em decorrência da obtenção de valor presente líquido positivo e rejeição daqueles que são negativos. Um dos pressupostos possíveis é que só haveria preocupação em utilizar métodos e mecanismos de apoio à análise se os projetos de investimento fossem estratégicos.

\section{Financiamentos de longo prazo}

Assim como foram tratados os ativos de longo prazo, os passivos de longo prazo são relevantes para a análise. Estes são representados pelas obrigações para com terceiros assumidas para financiar os ativos de longo e de curto prazos demandados pela organização (Van Horne, 1995).

Lambert (2006) reconhece que uma das decisões relevantes refere-se ao financiamento das operações da empresa, inclusive para compra de ativos de longo prazo. Jensen e Meckling (1976) tratam a questão do financiamento de longo prazo como variável relevante em termos de recursos, custos de financiamento e risco. Em decorrência do horizonte de retorno, os investimentos em tais ativos necessitam de financiamentos de longo prazo, independentemente se captados via capital próprio (patrimônio líquido) ou de terceiros (passivo). Entretanto há possibilidade de obter tais recursos por meio de aportes dos próprios sócios da empresa (patrimônio líquido), que, nesta pesquisa, são tratados como financiamentos de longo prazo, especificamente, os empréstimos de longo prazo captados junto a instituições financeiras ou fornecedores dos quais adquirem bens. Sendo assim, na pesquisa, são considerados como financiamentos de longo prazo somente os passivos não-circulantes, e não o patrimônio líquido da entidade.

Segundo Graham e Harvey (2002), existem duas teorias que explicam a escolha por determinada estrutura de capital: a teoria de trade-off (Brigham \& Ehrhardt, 2006), pela qual o limite para o endividamento é dado quando os custos gerados por este superam os benefícios gerados pela economia fiscal; e a teoria do pecking order (Myers, 1984), em que a assimetria de informações leva a empresa a colocar uma hierarquia na escolha de fontes de financiamento. Nesta teoria (pecking order), não há grau de alavancagem ótimo e a estrutura de capital passa a ser definida pela disponibilidade de fluxo de caixa.

Dado que todo o arcabouço do planejamento estratégico representa uma das formas de monitoramento de problemas de agência e considerando que a decisão de investimento em ativos de longo prazo ocorra por ocasião da estruturação do planejamento estratégico da organização, seria de esperar que a definição do tipo de financiamento fosse efetivada na mesma oportunidade. Assim, uma vez que opção pela forma de financiamento assume dimensão relevante no processo de decisão sobre investimentos de longo prazo, empresas com maior necessidade de financiar seus investimentos, via capital de terceiros, deveriam ampliar a aderência à utilização de instrumentos gerenciais, dada sua capacidade de proporcionar uma decisão mais acertada.

\section{Percepção de risco}

Quando trata o risco, explicitamente, a abordagem teórica não especifica quais tipos deveria levar em conta nem quais deveriam ser percebidos e, necessariamente, mitigados ou eliminados. Um projeto de investimento financiado com recursos de terceiros e um projeto idêntico, porém financiado com recursos próprios, podem receber diferentes percepções no que diz respeito à intensidade do risco inerente à decisão de investimento, dado que o financiamento terá um custo fixo para a organização, independentemente, de sua capacidade de geração de resultados. 
Ao tratar o risco nos projetos de investimento, pelo fato de que, na maior parte dos casos, os riscos desdobram-se e se misturam tornando a discussão complexa, não será feita a especificação de cada tipo de risco considerado pelo gestor, visto que o mais relevante é a atitude dele perante a expectativa do principal. Essa abordagem tem amparo na literatura, pois é esperado que o gestor tenha uma atitude não-passiva e, ao mesmo tempo, seja mitigada a perspectiva de que ele aja apenas em seu próprio favor (Subramaniam, 2006).

\section{Métodos de análise de investimentos e mecanismos adicionais}

Para Alkaraan e Northcott (2006), os métodos tradicionais de análise de investimentos são: (a) valor presente líquido do fluxo de caixa, (b) taxa interna de retorno, (c) payback simples e payback ajustado, (d) índice de lucratividade, e (e) taxa interna de retorno ajustada. Tais métodos são mencionados de forma abundante na literatura (Alkaraan \& Northcott, 2006; Arnold \& Hatzopoulos, 2000; Carr \& Tomkins, 1998; Haka, 2007; Lee, 1985; Pike, 1996; Rappaport, 1998; Verbeeten, 2006). Contudo, nesses trabalhos, não há consenso sobre qual dos métodos é o mais utilizado; sendo que, de maneira geral, as empresas optam por utilizar vários métodos conjuntamente (Arnold \& Hatzopoulos, 2000).

Stewart (1991) recomenda a abordagem do lucro residual, a qual denomina Economic Value Added (EVA), como método abrangente para análise e decisão sobre projetos de investimento, que se diferencia das demais pelo fato de não se basear em fluxos de caixa, mas no resultado econômico, permitindo análise, decisão e acompanhamento do investimento.

Apesar de haver farta oferta de instrumentos avaliativos de investimentos, o importante é que cada método se propõe a captar um aspecto do projeto: o valor agregado por ele (valor presente líquido e EVA), o spread de ganho do projeto (taxa interna de retorno), o período de recuperação do investimento levando em conta o custo de oportunidade (payback ajustado), dentre outros métodos. Porém, cumpre salientar que uma análise abrangente do projeto deverá levar em conta todas as diferentes perspectivas desses instrumentos.

Segundo Haka (2007), as metodologias para análise de investimentos envolvem métodos que são considerados principais e outros acessórios, como resultado da utilidade que assumem no suporte à tomada de decisão, a qual representa uma hierarquia de atributos desejados e decididos não apenas por questões isomórficas. Apesar dos benefícios que tais análises podem proporcionar, os métodos de avaliação de investimentos são alvo de críticas importantes.

Adicionalmente aos métodos de análise de investimentos, existem mecanismos que podem ser combinados com métodos e utilizados de maneira complementar, tais como: simulações, opções reais, análise beta, benchmarking, análise de cadeia de valor, etc. (Alkaraan \& Northcott, 2006; Carr \& Tomkins, 1998). Essas alternativas são decorrentes de diferentes perspectivas de se lidar com o risco dos projetos. Apesar das possibilidades comentadas, cumpre observar que intuição e capacidade de decidir sem métodos de avaliação de investimento tornam-se alternativas possíveis. Na verdade, essas habilidades é que proporcionam o processo decisório à luz das informações de apoio das análises financeiras, pois alguns fatores não podem ser expressos em números (Welsch, Hilton, \& Gordon, 1988). O que se questiona é a inexistência de estrutura formalizada e seu relacionamento com o processo de planejamento da empresa, dessa maneira, gerando lacuna na accountability dos gestores.

\section{Modelo Teórico e Hipóteses}

Como forma de aperfeiçoar a literatura, Hirsch, Michaels e Friedman (1987) consideram que ela demanda a utilização de teorias complementares, desde que tenham raízes epistemológicas compatíveis e possibilitem a confluência de pressupostos. Assim, o modelo teórico para o desenvolvimento empírico da pesquisa (Figura 1) considera elementos relacionados a projetos de 
investimento de LP: (a) financiamento e (b) vida útil dos projetos, (c) nível dos decisores - se conselho de administração ou outro - (d) percepção do risco, ambiente decisório - se no (e) planejamento estratégico ou (f) no orçamento - (g) métodos e (h) mecanismos de análise e (i) acompanhamento dos projetos.

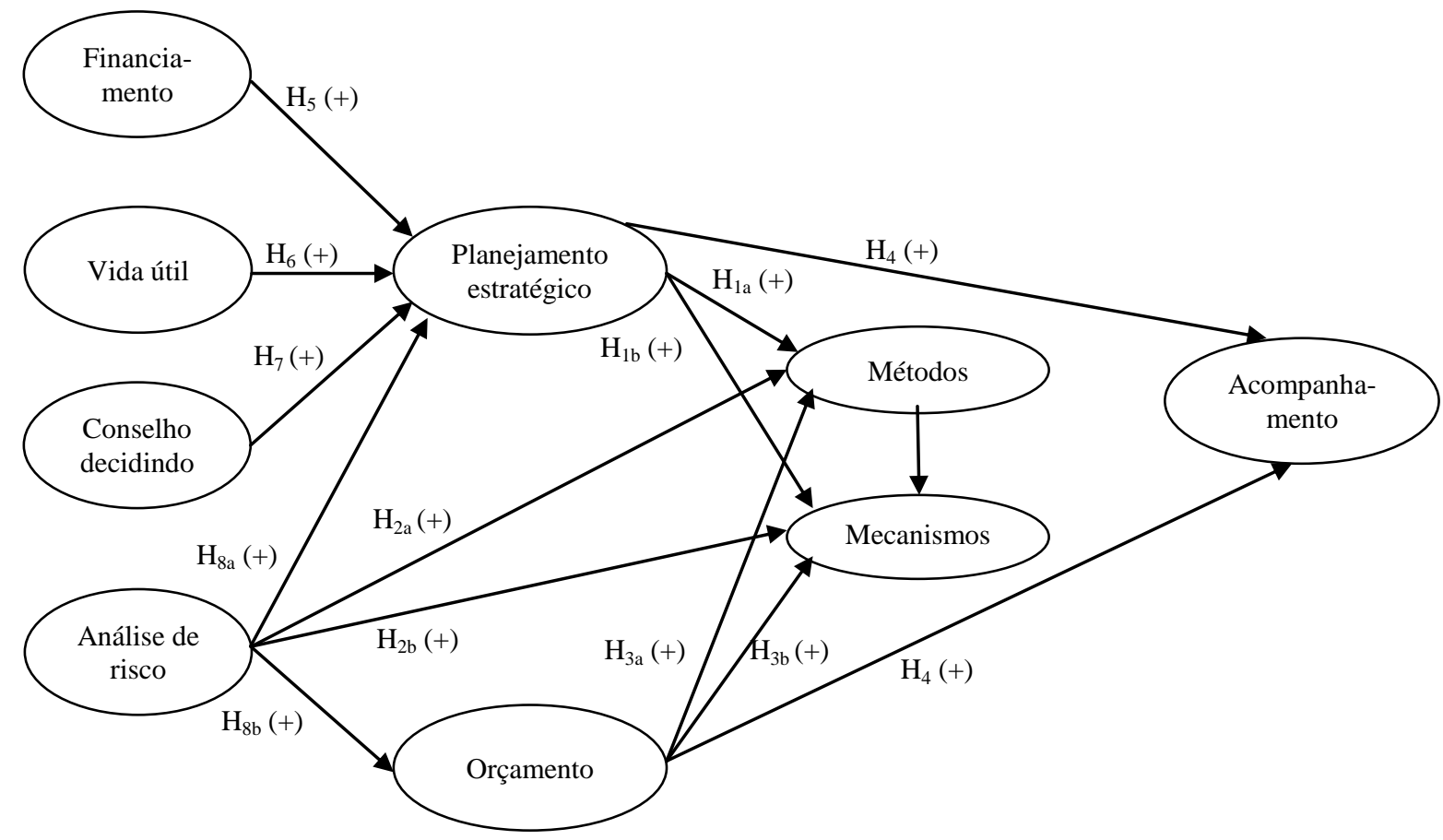

Figura 1. Modelo Hipotético.

A organização demanda estruturação para que possa dispor de contratos otimizados, entre o principal e o agente, e para que a delegação do primeiro para o segundo seja analisada e avaliada. Deste modo, o sistema de avaliação de desempenho é fundamental para nortear as decisões referentes às operações, aos financiamentos e aos investimentos (Lambert, 2006).

Para que faça sentido, o processo decisório deve ocorrer por meio de algum mecanismo que permita identificação, análise e discussão, no caso, do investimento; para isso, o processo formalizado de planejamento estratégico pode ser utilizado. Todavia, Eisenhardt (1989) indica que investimentos em sistemas de informações que permitam o planejamento podem proporcionar aperfeiçoamento para o processo de controle das ações dos gestores, assim, poder-se-ia considerar o orçamento como mecanismo para identificação, análise e discussão do investimento, o que deve ocorrer caso se trate de projeto não conhecido no momento da aprovação do planejamento estratégico.

Com relação ao financiamento dos investimentos, deveria ser analisado e aprovado junto com os investimentos de longo prazo. De qualquer forma, a combinação ou não dessas análises impacta sobre o risco da organização e no monitoramento do seu retorno. Finalmente, os métodos de avaliação de investimentos são instrumentos que permitem aos gestores entenderem, priorizarem e decidirem quanto a novos gastos, de acordo com as limitações e perfil de retorno. Os mecanismos adicionais correspondem às ferramentas que proporcionam análises, principalmente, evidenciando, mitigando e evitando o risco dos projetos.

As hipóteses desenvolvidas a partir dos constructos considerados foram segmentadas em duas partes: (a) relacionadas à utilização dos métodos e mecanismos de avaliação de investimentos; e (b) relacionadas aos instrumentos de planejamento. 


\section{Utilização de métodos e mecanismos de avaliação de investimentos}

A análise de novos projetos de investimento objetiva proporcionar aumento de valor à empresa (Lee, 1985; Rappaport, 1998; Welsch et al., 1988), os quais demandam financiamentos com custos específicos que devem ser pagos e remunerados. Para apoiar o processo decisório, uma análise prévia deve ser feita almejando avaliar se o retorno do investimento cobre o custo do financiamento. A aplicação dos métodos de avaliação de investimentos e mecanismos de análise pode constituir-se em forma de decidir, identificando, e/ou quantificando, e/ou mitigando o risco (Kim \& Farragher, 1981; Verbeeten, 2006), bem como direcionando o gerenciamento do projeto para que ele possa atingir o desempenho desejado.

Investigando a utilização destes métodos quanto à indicação, por parte das empresas, da natureza do investimento (estratégico x não-estratégico), Alkaraan e Northcott (2006) verificaram que há tendência na utilização dos métodos baseados na técnica do fluxo de caixa descontado (VPL e TIR), quando o investimento é considerado estratégico para a empresa. Assim, depreende-se que a concepção de investimento estratégico de cada empresa tende a orientar o emprego dos métodos e mecanismos explorados neste estudo. Portanto estabelece-se a seguinte hipótese: maior aderência à utilização dos métodos e mecanismos está associada positivamente ao projeto ser decidido no planejamento estratégico $\left(\mathbf{H}_{1}\right)$.

Em relação à análise do risco, há mecanismos adicionais que a consideram, sendo citados na literatura: (a) análise de sensibilidade, (b) ajuste do risco na taxa de desconto ou no encurtamento do período de payback, (c) análise de probabilidade, simulação e análise do beta (Alkaraan \& Northcott, 2006; Arnold \& Hatzopoulos, 2000; Pike, 1996). Os estudos de Pike (1996) e Alkaraan e Nortchcott (2006) indicam que a utilização desses mecanismos adicionais vem crescendo, bem como que a análise de sensibilidade, que é a mais simples, tem sido a mais utilizada pelas empresas. Os autores não encontraram nenhuma evidência de que haja diferença no tratamento do risco quando o investimento é considerado estratégico, sendo a análise de sensibilidade a técnica mais utilizada. Sendo assim, se a classificação não discrimina tipos de investimento, para fins de análise, ela não tem utilidade.

A utilização de mecanismos mais simples para medir o risco também foi enfatizada na amostra escolhida, no estudo de Arnold e Hatzopoulos (2000). Os respondentes apontaram que, se o gestor se preocupar excessivamente com a mensuração de probabilidades para utilização de modelos mais sofisticados, pode sentir-se pouco motivado a envidar esforços à realização do projeto. Contrariamente a essas afirmações, Verbeeten (2006) verificou a consideração do risco em empresas holandesas na utilização de mecanismos mais sofisticados, como as Opções Reais. Os resultados mostraram que, conforme as incertezas financeiras aumentam, há uma relação positiva com a adoção de mecanismos mais sofisticados de análise de investimentos. Já as incertezas de insumo de produção, sociais e mercadológicas não influenciam a adoção de mecanismos de análise. Normalmente, as empresas utilizam, simultaneamente, vários mecanismos de análise que consideram o risco.

Ho e Pike (1998), corroborando com Gaver e Gaver (1993), inferem que empresas com estratégias mais arriscadas e agressivas, com sistema de remuneração dos gestores focalizado no longo prazo e com sistema informacional que suporta informações de projetos de investimento, tendem a utilizar mecanismos mais sofisticados de tratamento de risco em análise de projetos, sugerindo que a maior aderência à utilização dos métodos e mecanismos esteja positivamente associada à preocupação com análise do risco percebido $\left(\mathrm{H}_{2}\right)$.

Em relação à frequência de uso dos métodos citados, Arnold e Hatzopoulos (2000) questionaram algumas empresas explorando se utilizavam sempre tais métodos. Os resultados indicaram que, apesar de VPL e TIR serem apontados como os métodos mais utilizados, metade das empresas respondentes não os emprega em todas as análises. Logo, o processo de análise considera fatores inerentes a cada projeto, o que pode sugerir que investimentos operacionais de menor valor possam ser aprovados sem o mesmo rigor de análise daqueles de maiores valores. Nesse sentido, a literatura permite que a lógica para o estabelecimento dos critérios e prioridades possa variar, 
dependendo das variáveis a elas relacionadas, sugerindo, assim, que a maior aderência à utilização dos métodos e mecanismos possa estar positivamente associada ao projeto ser decidido no orçamento $\left(\mathbf{H}_{3}\right)$.

\section{Decisão de investimento no planejamento estruturado}

Esta pesquisa leva em conta a existência, em algum grau, do processo formal de planejamento estruturado. Complementarmente, depreende-se que o plano de investimento contém as decisões de alocação de recursos nos ativos de longo prazo. O planejamento estratégico e o orçamento devem ser analisados de maneira separada, com perspectiva de que a decisão de investimentos possa ser tomada e deva estar refletida em um ou outro instrumento; isso conquanto a literatura indique o planejamento estratégico como instrumento que deveria conter tais decisões (Mintzberg, Ahlstrand, \& Lampel, 1998; Steiner, 1979).

Considerando que o orçamento de capital seja um processo de planejamento e controle dos gastos estratégicos e táticos em investimentos de longo prazo (Welsch et al., 1988), sua elaboração durante a montagem do instrumento de planejamento é demandada para que seja possível uma visão abrangente da carteira de investimentos, financiamentos e retorno. Nessa linha de raciocínio, Steiner (1979) indica que os projetos deveriam ser aprovados a partir de um instrumento estratégico e que o orçamento apoiaria a implementação e o acompanhamento de tais decisões. Desse modo, a partir da percepção de que existam projetos que não são aprovados no planejamento estratégico, mas sim no orçamento, questiona-se se (a) ocorrerá acompanhamento e (b) em que abrangência? Assim, estabelece-se a seguinte hipótese: projetos aprovados no planejamento estratégico são acompanhados de maneira mais estruturada do que projetos aprovados no orçamento $\left(\mathrm{H}_{4}\right)$.

Retomando-se a indicação de Lambert (2006), que ativos de longo prazo necessitam de recursos de longo prazo para o seu financiamento, e, ainda, considerando-se a valorização de tal decisão por parte de Jensen e Meckling (1976), desenvolveu-se a seguinte hipótese: a maior necessidade de definição de financiamento e custo de oportunidade está associada positivamente à inclusão do projeto no planejamento estratégico $\left(\mathrm{H}_{5}\right)$.

Quanto à característica estratégica dos investimentos em ativos de LP, Slagmulder (1997) indica como sendo investimento estratégico aquele que auxilia a empresa a atingir seus objetivos de LP. Nesse sentido, pressupondo-se que a ideia de investimento relevante esteja associada à continuidade da organização, estabelece-se a hipótese: o maior horizonte de vida útil está associado positivamente à inclusão do projeto no planejamento estratégico $\left(\mathbf{H}_{6}\right)$.

Ainda com relação às hipóteses, apoiando-se em Jensen e Meckling (1976), explora-se a figura do principal como sendo o conselho de administração da organização, o que conduz à seguinte hipótese: processos decisórios que envolvem o conselho de administração são incluídos no planejamento estratégico $\left(\mathbf{H}_{7}\right)$. Essa hipótese tem por pretensão examinar a relevância do nível hierárquico em que a decisão é tomada. Por fim, salienta-se que as argumentações precedentes (seção Utilização de Métodos e Mecanismos de Avaliação de Investimentos) relativas à análise do risco sugerem que a percepção quanto ao risco impacta positivamente a definiçãa da decisão de aceitação do projeto ocorrer no planejamento estratégico ou no orçamento $\left(\mathbf{H}_{8}\right)$.

A Tabela 1 reúne as hipóteses da pesquisa e as fontes que as respaldam. 
Tabela 1

Hipóteses da Pesquisa

\begin{tabular}{|c|c|c|}
\hline & Hipótese & Referências \\
\hline $\begin{array}{l}0 \\
0 \\
0 \\
0 \\
0 \\
0 \\
0 \\
0\end{array}$ & $\begin{array}{l}\mathrm{H}_{1} \text { : maior aderência à utilização dos métodos e mecanismos está } \\
\text { associada positivamente ao projeto ser decidido no planejamento } \\
\text { estratégico; }\end{array}$ & $\begin{array}{l}\text { Alkaraan e Northcott (2006) } \\
\text { Ho e Pike (1998) } \\
\text { Kim e Farragher (1981) } \\
\text { Verbeeten (2006) }\end{array}$ \\
\hline 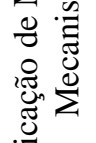 & $\begin{array}{l}\mathrm{H}_{2} \text { : maior aderência à utilização dos métodos e mecanismos está } \\
\text { associada positivamente à preocupação com análise do risco } \\
\text { percebido; }\end{array}$ & $\begin{array}{l}\text { Alkaraan e Northcott (2006) } \\
\text { Arnold e Hatzopoulos (2000) } \\
\text { Pike (1996) }\end{array}$ \\
\hline 定 & $\begin{array}{l}\mathrm{H}_{3} \text { : maior aderência à utilização dos métodos e mecanismos está } \\
\text { associada positivamente ao projeto ser decidido no orçamento. }\end{array}$ & $\begin{array}{l}\text { Arnold e Hatzopoulos (2000) } \\
\text { Ho e Pike (1998) }\end{array}$ \\
\hline
\end{tabular}

$\mathrm{H}_{4}$ : projetos aprovados no planejamento estratégico são acompanhados de maneira mais estruturada do que os projetos aprovados no orçamento (o coeficiente estrutural entre projeto e acompanhamento é maior do que o coeficiente entre orçamento e

Steiner (1979) acompanhamento);

$\mathrm{H}_{5}$ : maior necessidade de definição de financiamento e custo de oportunidade está associada positivamente à inclusão do projeto no planejamento estratégico;

$\mathrm{H}_{6}$ : maior horizonte de vida útil está associado positivamente à inclusão do projeto no planejamento estratégico;

$\mathrm{H}_{7}$ : processos decisórios que envolvem o conselho de administração são incluídos no planejamento estratégico;

Jensen e Meckling (1976)

Lambert (2006)

Butler et al. (1991)

Marsh et al. (1988)

Slagmulder (1997)

Jensen e Meckling (1976)

$\mathrm{H}_{8}$ : a percepção de risco do projeto impacta positivamente na definição da decisão de aceitação do projeto ocorrer no planejamento estratégico ou no orçamento.

Alkaraan e Northcott (2006)

Arnold e Hatzopoulos (2000)

Gaver e Gaver (1993)

Ho e Pike (1998)

Verbeeten (2006)

\section{Setor da economia e porte}

Alguns setores, por tradição em investimentos de longo prazo e por caracterização ao risco, proporcionam forte aderência ao modelo conceitual (Verbeeten, 2006). Em relação aos setores analisados, há uma correlação positiva entre o setor e a utilização de mecanismos mais sofisticados, os setores financeiros, de construção civil e de utilidade pública (gás, energia, telefonia, etc.), que apresentam a utilização de tais mecanismos na decisão do investimento.

O tamanho da empresa é outra variável que influencia a adoção de mecanismos de análise: quanto maior a empresa maior a disponibilidade de recursos empregados para análise financeira de investimentos. Esta pesquisa deixará de tratar a variável porte, pois todas as empresas são de grande porte, logo, uma estratificação entre setores criaria um viés adicional devido ao tamanho amostral limitado. 


\section{Metodologia}

A pesquisa é de natureza predominantemente descritiva, com abordagem quantitativa. As empresas listadas na publicação Melhores \& Maiores (Editora Abril, 2009) constituem o universo de 1.825 organizações. Considerando-se este grupo, verificou-se que, em 900 empresas, houve evolução de investimentos em ativos de LP no período 2004-2008. Deste conjunto de 900 organizações (população-alvo), obteve-se uma amostra de 82 empresas, decorrente de uma estratégia de conveniência. A classificação das empresas, quanto ao seu porte, foi efetuada em conformidade com o disposto pelo Banco Nacional de Desenvolvimento Econômico e Social (BNDES, 2010).

O questionário foi composto de questões fechadas distribuídas em blocos. Foram mapeadas informações acerca: (a) da percepção quanto à relevância dos investimentos de longo prazo; (b) das características dos investimentos (estratégico x não-estratégico); (c) dos mecanismos e métodos auxiliares empregados na análise de investimentos; (d) dos instrumentos de gestão disponíveis na organização; e (e) da hierarquia de tomada de decisão.

A coleta de dados foi realizada entre janeiro e março de 2010, por meio de questionário eletrônico. As informações sobre formação acadêmica, tempo decorrido desde tal formação e ocupação profissional dos respondentes indicaram adequada maturidade profissional, de nível hierárquico e de formação em relação ao tema pesquisado.

$\mathrm{Na}$ estrutura do questionário, as variáveis consideradas para a operacionalização dos constructos, no modelo da pesquisa, tiveram a abordagem reflexiva demonstrada (Jarvis, MacKenzie, \& Podsakoff, 2003). As variáveis relevantes para a análise decorrem dos constructos teóricos e das hipóteses desenvolvidas na seção Modelo Teórico e Hipóteses.

Empregou-se a técnica de modelagem de equações estruturais (MME) para tratamento dos dados, que se mostra oportuna pelas possibilidades de: (a) estimar modelos em uma variável dependente que se torna independente em subsequentes relações de dependência (path analysis) e (b) incluir variáveis latentes mensuradas indiretamente (Hair, Anderson, Tatham, \& Black, 2005). Os dados foram processados no software SmartPLS 2.0.M3 (Ringle, Wende, \& Will, 2005). Desse modo, a escolha pela referida técnica justifica-se pelo fato de permitir "separar relações para cada conjunto de variáveis dependentes" (Hair et al., 2005, p. 34), possibilitando, assim, o teste simultâneo das inúmeras relações de dependência, como ilustrado na Figura 1.

\section{Análise de Resultados e Discussão}

\section{Aspectos descritivos da pesquisa de campo}

Os elementos para a caracterização das empresas respondentes da pesquisa com objetivo de proporcionar discriminação levaram em conta: (a) setor da economia, (b) ter ou não suas ações negociadas em bolsa, (c) participação do ativo de longo prazo sobre o total do ativo, (d) faturamento e (e) índice de endividamento. Quanto à distribuição setorial, o critério seguiu a definição da Revista Melhores \& Maiores e verificou-se que existe concentração em alguns campos, como energia, alimentos/bebidas e fumo e siderurgia.

Com relação à distribuição em termos de participação no mercado acionário, a maior parte das empresas não possui ações cotadas em bolsa $(79,27 \%)$. No que se refere ao ativo não-circulante, este corresponde à parcela relevante do seu ativo total (na maior parte dos setores acima de $50 \%$ ). O faturamento bruto do ano de 2008 indica, de acordo com critérios do BNDES (2010), que todas as empresas são de grande porte, contudo esta dimensão tem uma amplitude muito grande, variando de milhões a bilhões de dólares. As empresas analisadas mostram-se altamente capitalizadas, o que 
corresponde a uma característica muito frequente no país. Consequentemente, é de se esperar que: (a) a grande participação de empresas com comportamento assemelhado frente aos projetos de investimento se apresente como fator que traz um viés para a valorização do investimento em ativos de LP; (b) exista relativa homogeneidade em termos de elementos encontrados nas empresas que se destacam pela disponibilidade de recursos que o porte proporciona; e (c) diferenças que são comumente citadas entre empresas que têm ações em bolsa e as que não têm sejam encontradas.

Quanto aos respondentes do questionário, 96,3\% têm formação acadêmica, sendo 65,8\% em Ciências Contábeis e quase $20 \%$ em Administração. No que diz respeito ao cargo ocupado pelos mesmos, 48 eram diretores, superintendentes, gerentes ou coordenadores na ocasião da coleta de dados. Os demais colaboradores assumiam os cargos de analista, especialista ou contador nas empresas pesquisadas. Pouco mais de $80 \%$ dos respondentes ocupavam os cargos recém-descritos por um período superior a cinco anos.

\section{Análises univariadas}

Inicialmente, apresenta-se a estatística descritiva dos indicadores utilizados na mensuração das variáveis latentes (as cargas fatoriais apresentadas neste momento foram obtidas na estimação do modelo completo). Assim, explora-se como os respondentes percebem os projetos de investimentos. Nesse sentido, a Tabela 2 indica que os três métodos mais utilizados são o valor presente líquido do fluxo de caixa, a taxa interna de retorno e o payback simples. Isso confirma achados anteriores para VPL, indicado por $54 \%$ dos respondentes como o método mais importante, e para TIR, indicada por $38 \%$ dos respondentes como o método mais relevante no seu ranking. Entretanto a distância de valorização do payback para os dois métodos pode ser preocupante pelo fato de que as análises, em alguns casos, não levaram em conta o horizonte de retorno, o que se constitui em variável relevante dentro da análise de risco de um projeto. Quanto ao EVA, sua estratégia é seletiva, sendo utilizado por grupo menor de entidades.

Tabela 2

Métodos de Análise de Investimentos

\begin{tabular}{|c|c|c|c|c|c|c|c|c|c|}
\hline \multirow{2}{*}{ Indicadores } & \multicolumn{4}{|c|}{ Respostas } & \multirow{2}{*}{ Missing } & \multirow{2}{*}{$\begin{array}{l}\text { Ranking de } \\
\text { utilização }\end{array}$} & \multirow{2}{*}{ Média } & \multirow{2}{*}{$\begin{array}{l}\text { Desvio } \\
\text { padrão }\end{array}$} & \multirow{2}{*}{$\begin{array}{l}\text { Carga } \\
\text { fatorial }\end{array}$} \\
\hline & $0^{\mathrm{a}}$ & $1^{\mathrm{b}}$ & $2^{c}$ & $3^{\mathrm{d}}$ & & & & & \\
\hline Valor presente do fluxo de caixa & 8 & 0 & 74 & 0 & 0 & $1^{\circ} / 54 \%$ & 1,8 & 0,59 & $0,631^{*}$ \\
\hline Taxa interna de retorno & 6 & 0 & 75 & 0 & 1 & $2^{\circ} / 38 \%$ & 1,9 & 0,52 & $0,594^{*}$ \\
\hline Taxa interna de retorno modificada & 38 & 0 & 42 & 0 & 2 & & 1,1 & 0,99 & $0,499^{*}$ \\
\hline Payback simples & 17 & 0 & 64 & 0 & 1 & $3 \circ / 21 \%$ & 1,6 & 0,81 & $0,481^{*}$ \\
\hline $\begin{array}{l}\text { Payback ajustado p/taxa de custo de } \\
\text { oportunidade }\end{array}$ & 29 & 0 & 51 & 0 & 2 & & 1,3 & 0,95 & $0,621^{*}$ \\
\hline Índice de lucratividade & 20 & 0 & 60 & 0 & 2 & & 1,5 & 0,86 & $0,537^{*}$ \\
\hline Economic value added (EVA) & 38 & 0 & 41 & 0 & 3 & & 1,0 & 0,98 & $0,725^{*}$ \\
\hline
\end{tabular}

Nota. Escala ordinal utilizada como intervalar.

a não usa; ${ }^{\mathrm{b}}$ usa em projeto não-estratégico; ${ }^{\mathrm{c}}$ usa em projeto estratégico; ${ }^{\mathrm{d}}$ usa em todos os projetos.

Complementarmente, a Tabela 3 reúne informações acerca dos mecanismos auxiliares de análise de investimentos. São destaques dos mecanismos auxiliares as simulações, que podem ser encontradas da maneira mais simples, como um teste de sensibilidade, ou mesmo um conjunto de elementos que inclua outros mecanismos. 
Tabela 3

\section{Mecanismos Auxiliares de Análise de Investimentos}

\begin{tabular}{lccc}
\hline \multicolumn{1}{c}{ Indicadores } & Média & Desvio padrão & Cargas fatoriais \\
\hline São feitas simulações para análise de risco & 4,0 & 1,02 & $0,787^{*}$ \\
Opções reais & 3,3 & 1,27 & $0,658^{*}$ \\
Análise beta dos projetos & 2,8 & 1,31 & $0,676^{*}$ \\
Benchmarking & 3,6 & 1,10 & $0,713^{*}$ \\
Análise de Cadeia de Valor & 3,4 & 1,2 & $0,776^{*}$ \\
\hline
\end{tabular}

Nota. Escala Tipo Likert de 5 pontos (1 a 5).

* todas as cargas fatoriais significantes $(\mathrm{p}<0,0001)$.

O acompanhamento de um projeto é vital para o gerenciamento da organização (Tabela 4). Nesse sentido, a constatação de que se realiza o acompanhamento do projeto após sua implementação é muito relevante para o gerenciamento do retorno e, consequentemente, para a gestão da organização. $\mathrm{O}$ fato de os diretores e gerentes serem cobrados pelos resultados dos projetos é algo consistente com a literatura e relevante para que o interesse sobre o resultado persista (Subramaniam, 2006). Embora este último elemento não seja tão predominante como os demais, é relativamente alto, reforçando a relevância.

Tabela 4

\section{Acompanhamento}

\begin{tabular}{lccc}
\hline \multicolumn{1}{c}{ Indicadores } & Média & $\begin{array}{c}\text { Desvio } \\
\text { padrão }\end{array}$ & $\begin{array}{c}\text { Cargas } \\
\text { fatoriais }\end{array}$ \\
\hline O acompanhamento dos projetos depois de sua implementação ocorre na empresa & 0,9 & 0,33 & $0,729^{*}$ \\
A geração de relatórios sobre o acompanhamento de projetos existe na empresa & 0,9 & 0,34 & $0,775^{*}$ \\
$\begin{array}{l}\text { Os projetos de investimentos implementados são acompanhados para identificar o } \\
\text { retorno real }\end{array}$ & 4,1 & 1,07 & $0,780^{*}$ \\
$\begin{array}{l}\text { Os gestores (diretores e/ou gerentes) recebem relatórios sobre desempenho dos } \\
\text { projetos }\end{array}$ & 4,2 & 0,98 & $0,816^{*}$ \\
$\begin{array}{l}\text { O desempenho dos diretores inclui análise sobre projetos implementados } \\
\text { O desempenho dos gerentes inclui análise sobre projetos implementados }\end{array}$ & 3,6 & 1,36 & $0,714^{*}$ \\
\hline
\end{tabular}

Nota. Os dois primeiros itens foram mensurados em uma escala dummy $(1=\operatorname{sim}$; 0 = não $)$ e os demais em uma escala do tipo Likert de 5 pontos ( 1 a 5 ).

* todas as cargas fatoriais significantes $(\mathrm{p}<0,0001)$

O momento e o instrumento pelos quais o projeto de investimento é aprovado e considerado como parte do processo formal de planejamento são fundamentais dentro do modelo de gestão (Tabela 5). Assim, a figura do planejamento estratégico é predominante no processo de aprovação dos projetos, o que corrobora a teoria. Entretanto, a aprovação dos projetos estratégicos também ocorre no orçamento e, em menos casos, eles não são aprovados por meio de um instrumento formal, o que implica em um desvio da aderência à teoria e aumenta o risco de gerenciamento de retorno. Por sua vez, os projetos não-estratégicos são aprovados no orçamento. A partir da pesquisa, pode-se perceber que o termo estratégico não discrimina o tipo de projeto, nem mesmo a diferenciação no seu financiamento ou processo decisório. 
Tabela 5

\section{Perguntas para Obtenção de Dados sobre a Decisão Ocorrer no Planejamento Estratégico}

\begin{tabular}{|c|c|c|c|c|c|c|c|}
\hline \multirow{2}{*}{ Indicadores } & \multicolumn{3}{|c|}{ Respostas } & \multirow{2}{*}{ Missing } & \multirow{2}{*}{ Média } & \multirow{2}{*}{$\begin{array}{l}\text { Desvio } \\
\text { padrão }\end{array}$} & \multirow{2}{*}{$\begin{array}{l}\text { Cargas } \\
\text { fatoriais }\end{array}$} \\
\hline & $0^{\mathrm{a}}$ & $1^{\mathrm{b}}$ & $2^{c}$ & & & & \\
\hline O planejamento estratégico formalizado existe na empresa & 13 & 69 & 0 & 0 & 0,8 & 0,37 & $0,614^{*}$ \\
\hline O projeto de investimento estratégico é aprovado no ... & 7 & 34 & 41 & 0 & 1,4 & 0,64 & $0,879^{*}$ \\
\hline O projeto de investimento não-estratégico é aprovado no ... & 5 & 67 & 10 & 0 & 1,1 & 0,42 & $0,735^{*}$ \\
\hline
\end{tabular}

Nota. O primeiro item foi mensurado em uma escala dummy $\left({ }^{\mathbf{a}}\right.$ não; ${ }^{\mathbf{b}}$ sim) e os demais em uma escala de 3 pontos. ${ }^{\mathbf{a}}$ decisão pode ocorrer em ambos os momentos; ${ }^{\mathbf{b}}$ decisão no orçamento; $\mathrm{e}^{\mathbf{c}}$ decisão no planejamento estratégico.

todas as cargas fatoriais significantes $(\mathrm{p}<0,01)$.

Quanto ao financiamento dos projetos de investimento, pode-se perceber (Tabela 6) que nem todo o investimento estratégico tem o seu financiamento definido no planejamento estratégico; parte dos projetos não-estratégicos tem seus financiamentos configurados no mesmo instrumento. Este achado é consistente com o anterior, pois o termo estratégico não necessariamente se refere a projeto que foi decidido no instrumento planejamento estratégico. A definição do custo de oportunidade também pode ocorrer da mesma maneira, ou seja, sem uma associação com o fato de ser ou não definido no planejamento estratégico. Uma parte relevante dos projetos estratégicos acaba sendo aprovada no orçamento, além disso, a definição do custo de oportunidade também ocorre no momento da estruturação do orçamento. A consequência desse deslocamento da decisão do projeto para o momento de estruturação do orçamento pode ocasionar a descaracterização de uma ação estratégica, que pode se transformar em tática, ou mesmo na sua confirmação. A pesquisa não conseguiu captar e dimensionar essa possibilidade, mas esse achado levanta uma oportunidade de discussão sobre o risco assumido, pois a organização decidiu um investimento sem ter o correspondente financiamento de longo prazo.

Tabela 6

\section{Perguntas para Obtenção de Dados sobre Financiamento}

\begin{tabular}{lccccccccc}
\hline \multicolumn{1}{c}{ Indicadores } & \multicolumn{2}{c}{ Respostas } & Missing & Média & $\begin{array}{c}\text { Desvio } \\
\text { padrão }\end{array}$ & $\begin{array}{c}\text { Cargas } \\
\text { fatoriais }\end{array}$ \\
\hline Tipo de financiamento para o projeto de investimento estratégico & 11 & 35 & 35 & 1 & 1,3 & 0,69 & $0,847^{*}$ \\
$\begin{array}{l}\text { Tipo de financiamento para o projeto de investimento não- } \\
\text { estratégico }\end{array}$ & 11 & 53 & 17 & 1 & 1,1 & 0,58 & $0,788^{*}$ \\
Taxa de custo de oportunidade previamente definida & 9 & 34 & 36 & 3 & 1,3 & 0,66 & $0,780^{*}$ \\
\hline
\end{tabular}

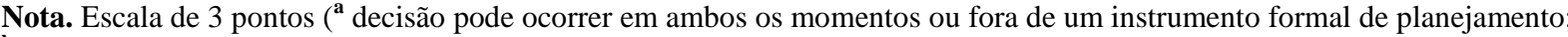
${ }^{\mathbf{b}}$ decisão no orçamento; $\mathrm{e}^{\mathbf{c}}$ decisão no planejamento estratégico).

todas as cargas fatoriais significantes $(\mathrm{p}<0,0001)$.

O perfil das empresas pesquisadas provocou um viés de projetos alongados e isso está refletido na Tabela 7, indicando que existe uma tendência de projetos de relativo maior longo prazo e, consequentemente, com risco de cenário diferenciado. Assim, seria de se esperar que instrumentos fossem considerados para analisar e suportar o processo decisório e mesmo para monitorar o desenvolvimento dos investimentos no horizonte tático dessas organizações. 
Tabela 7

\section{Perguntas para Mensuração da Vida Útil}

\begin{tabular}{lccc}
\hline \multicolumn{1}{c}{ Indicadores } & Média & $\begin{array}{c}\text { Desvio } \\
\text { padrão }\end{array}$ & $\begin{array}{c}\text { Cargas } \\
\text { fatoriais }\end{array}$ \\
\hline A maior parte dos nossos projetos tem ativos com vida útil de 11-20 anos & 3,2 & 1,51 & $0,950^{*}$ \\
A maior parte dos nossos projetos tem ativos com vida útil maior que 20 anos & 3,2 & 1,49 & $0,373^{* *}$ \\
\hline
\end{tabular}

Nota. Escala Likert de 5 pontos (1 a 5).

* carga fatorial significante $(\mathrm{p}<0,001) ;{ }^{* *}$ carga fatorial não significante, porém, foi mantido no modelo de mensuração por questão de validade de conteúdo (Little, Lindenberger, \& Nesselroade, 1999).

A perspectiva de risco foi captada por meio de três itens (Tabela 8), são eles o desenvolvimento da análise de risco de um modo geral, captada de forma reversa, a análise individualizada e a atribuição de risco por projeto. As respostas permitem entender que há análise de cada projeto, contudo a atribuição de risco individualizada, por projeto, não é tão frequente, o que, do ponto de vista de processo decisório, empobrece a análise.

Tabela 8

Perguntas para Obtenção de Dados sobre a Análise de Risco

\begin{tabular}{lccc}
\hline \multicolumn{1}{c}{ Indicadores } & Média & $\begin{array}{c}\text { Desvio } \\
\text { padrão }\end{array}$ & $\begin{array}{c}\text { Cargas } \\
\text { fatoriais }\end{array}$ \\
\hline Análise de risco dos projetos de investimento não é feita (Reversa) & 4,1 & 1,34 & $0,507^{*}$ \\
A análise de risco de cada projeto é desenvolvida & 4,2 & 0,81 & $0,873^{*}$ \\
Atribuição de risco diferenciado por projeto & 3,5 & 1,18 & $0,894^{*}$ \\
\hline
\end{tabular}

Nota. Escala Likert de 5 pontos (1 a 5 ).

* todas as cargas fatoriais significantes $(\mathrm{p}<0,01)$.

Na maioria das empresas (76), a decisão do projeto de investimento é feita pelo conselho de administração; 2 citaram outros níveis hierárquicos (havia 4 dados faltantes). Dada essa homogeneidade de respostas (variabilidade quase nula), essa variável também não apresentou correlação com as demais variáveis do modelo estrutural. Complementarmente, 80 respondentes declararam que há orçamento formalizado na empresa. Novamente, o consenso explica a falta de correlação dessa variável com as demais variáveis do modelo estrutural.

Quanto ao setor da economia, embora a análise tenha sido iniciada com mais de um agrupamento de setores, apenas as empresas evidenciadas como serviço público/energia e siderurgia, pelas citações na literatura, foram separadas das demais. A pequena quantidade de empresas de cada setor limitou o potencial de discriminação nesse quesito.

\section{Análises multivariadas}

O modelo apresentado na Figura 1 foi estimado por PLS-PM (Partial least squares path modeling). Comparado a outras opções de análise estatística, apresenta as seguintes vantagens: (a) permite a utilização de variáveis latentes, o que não seria possível com outras alternativas; (b) PLSPM estima o modelo de mensuração (relação entre os indicadores e as variáveis latentes) e o modelo estrutural (relações entre as variáveis latentes) simultaneamente; (c) LISREL tem suposição de normalidade dos dados, enquanto o PLS-PM não tem suposições quanto à distribuição dos dados (Henseler, Ringle, \& Sinkovics, 2009); e (d) LISREL requer amostras superiores a 200 casos, enquanto, na presente pesquisa, o PLS-PM demandou uma amostra de 82 casos (quantidade suportada 
por Henseler et al., 2009) para atingir um poder estatístico de $80 \%$, que é o mínimo recomendado por Hair, Anderson, Tatham e Black (2005), detectando como significante efeitos de tamanho médio $\left(\mathrm{R}^{2}=\right.$ $13 \%)$.

\section{Avaliação do modelo de mensuração}

A validade convergente foi avaliada pelas cargas fatoriais, que apresentaram valores significantes, com exceção de um indicador da variável latente: Vida útil (comentado na Tabela 7); avaliação também pela variância média extraída (VME), acima de 0,5 (Fornell \& Larcker, 1981), com exceção da variável latente Métodos (Tabela 9). Optou-se por manter todos os itens para não prejudicar a validade de conteúdo.

Tabela 9

Avaliação da Validade e Confiabilidade dos Construtos

\begin{tabular}{|c|c|c|c|c|c|c|c|c|c|}
\hline Variável Latente & 1 & 2 & 3 & 4 & 5 & 6 & 7 & 8 & 9 \\
\hline \multicolumn{10}{|c|}{ PARTE A: Matriz de correlação entre variáveis latentes } \\
\hline 1 - Acompanhamento & $0,751^{* * *}$ & & & & & & & & \\
\hline 2 - Análise do risco & $0,579^{* *}$ & $\mathbf{0 , 7 7 8 ^ { * * * }}$ & & & & & & & \\
\hline 3 - Conselho decidindo & 0,095 & 0,199 & $1,000^{* *}$ & & & & & & \\
\hline 4 - Financiamento & $0,360^{* * *}$ & $0,388^{* *}$ & $-0,008$ & $0,806^{* *}$ & & & & & \\
\hline 5 - Mecanismos & $0,483^{* *}$ & $0,680^{* *}$ & 0,080 & $0,366^{* *}$ & $\mathbf{0 , 7 2 4}{ }^{* *}$ & & & & \\
\hline 6 - Métodos & $0,234^{*}$ & $0,220^{*}$ & $-0,037$ & $0,358^{* *}$ & $0,331^{* *}$ & $0,589^{* *}$ & & & \\
\hline 7 - Orçamento & $-0,044$ & $-0,038$ & $-0,027$ & $-0,117$ & $-0,012$ & 0,206 & $1,000^{* *}$ & & \\
\hline 8 - Plano Estratégico & $0,375^{* *}$ & $0,306^{* *}$ & 0,188 & $0,523^{* *}$ & $0,302^{* *}$ & $0,247^{*}$ & $0,313^{* *}$ & $\mathbf{0 , 7 5 1 ^ { * * }}$ & \\
\hline 9 - Vida útil do ativo & 0,139 & 0,143 & 0,162 & 0,203 & 0,128 & 0,205 & 0,076 & 0,131 & $0,722^{* *}$ \\
\hline \multicolumn{10}{|c|}{ PARTE B: Validade e Confiabilidade } \\
\hline Variância média extraída & 0,56 & 0,61 & 1,00 & 0,65 & 0,52 & 0,35 & 1,00 & 0,56 & 0,52 \\
\hline Confiabilidade composta & 0,89 & 0,81 & 1,00 & 0,85 & 0,85 & 0,79 & 1,00 & 0,79 & 0,65 \\
\hline
\end{tabular}

Nota. Valores em negrito (na diagonal) são a raiz quadrada da variância média extraída (VME). Amostra com 82 casos. "correlações significativas a 5\% (bicaudal); ${ }^{* *}$ correlações significativas a 1\% (bicaudal).

Para todas as variáveis latentes, houve validade discriminante, assim como a confiabilidade apresentou valor satisfatório, acima de 0,7 (Fornell \& Larcker, 1981).

\section{Avaliação do modelo estrutural e discussão}

O modelo indica os coeficientes estruturais estimados pelo software SmartPLS 2.0.M3 (Ringle et al., 2005). Os valores $p$ foram estimados por bootstrap com amostra de 82 casos e 1.000 reamostragens. O setor da economia foi utilizado como variável de controle, porém o resultado ficou alinhado com a abordagem de Alkaraan e Northcott (2006), que não encontraram evidências de que o setor influenciasse na utilização de métodos e mecanismos, mas destoa dos achados de Verbeeten (2006). A Figura 2 resume os resultados para cada uma das hipóteses (as setas pontilhadas indicam as hipóteses que não foram validadas). 


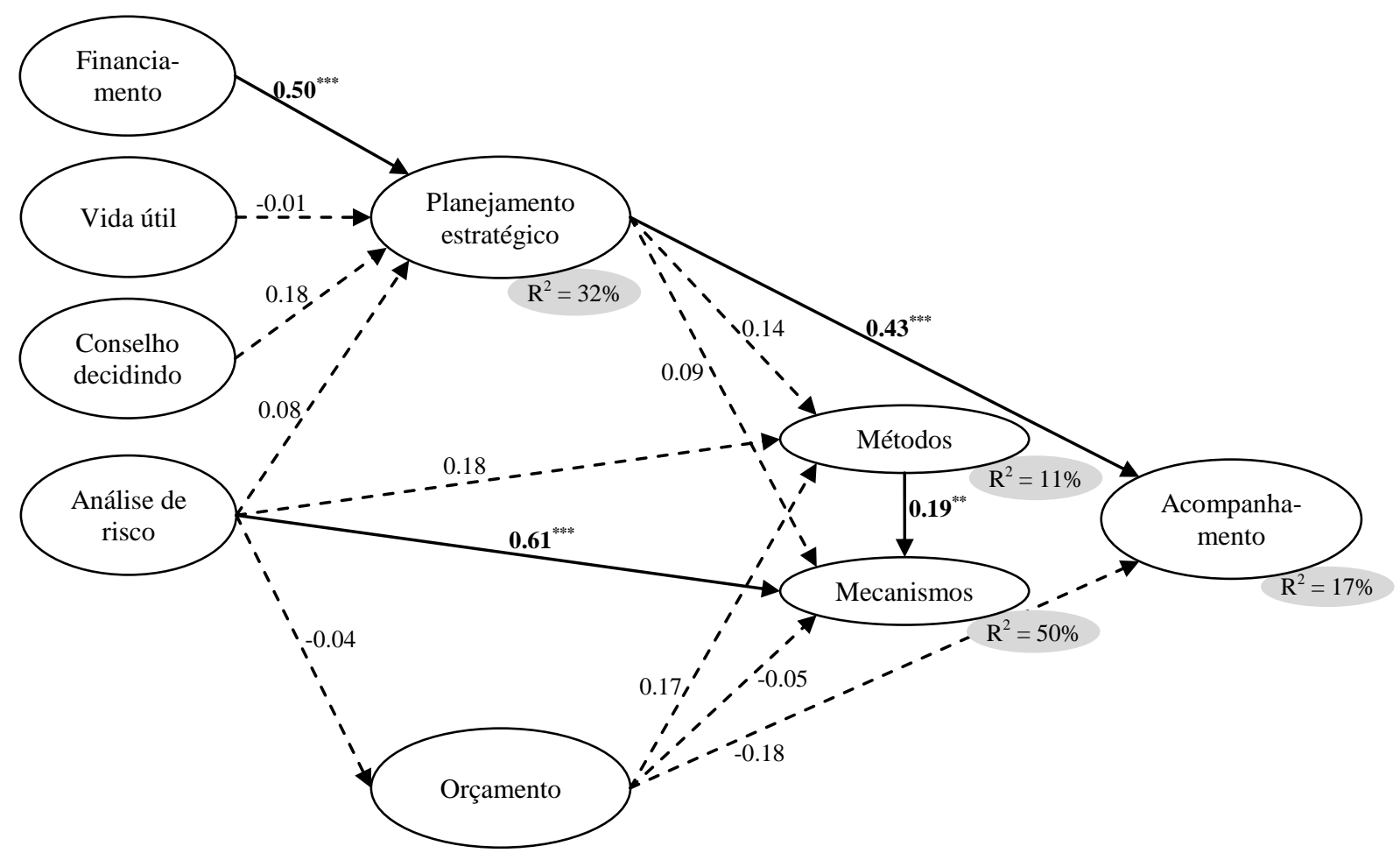

Figura 2. Modelo Estrutural.

Nota. Significância estimada por bootstrap com n $=82$ e 1.000 reamostragens; o setor foi considerado como uma variável de controle $(0=$ serviços públicos e siderurgia; $1=$ outros setores $)$, mas não apresentou efeito significante; Cohen (1977) classifica valores de $\mathrm{R}^{2}$ superiores a $13 \%$ como efeito médio e superiores a $26 \%$ como grande.

${ }^{* *} \mathrm{p}<0,05$, bicaudal; ${ }^{* * *} \mathrm{p}<0,01 ;$ seta tracejada = coeficiente não significante.

A primeira hipótese (maior aderência à utilização dos métodos e mecanismos está associada positivamente ao projeto ser decidido no planejamento estratégico) não foi confirmada. Significa que não se pode dizer que os projetos aprovados no planejamento estratégico diferenciam a utilização dos métodos e mecanismos. A segunda hipótese (maior aderência à utilização dos métodos e mecanismos está associada positivamente à preocupação com análise do risco percebido) não foi confirmada para os métodos, mas foi aceita no que se refere aos mecanismos $(\beta=0,61, p<0,01)$, indicando que a utilização dos mecanismos é influenciada pela percepção e valorização do risco. Embora o estudo não corrobore a abordagem de Verbeeten (2006) e Alkaraan e Northcott (2006) no sentido de que a percepção do risco impacta a utilização de métodos de análise de investimento, vai ao encontro das conclusões de Verbeeten (2006) quanto ao impacto da percepção do risco sobre a utilização dos mecanismos de apoio à análise de investimentos.

A terceira hipótese (maior aderência à utilização dos métodos e mecanismos está associada positivamente ao projeto ser decidido no orçamento) não foi confirmada. Assim, expressa que não se pode inferir que os projetos aprovados no orçamento tenham a mesma utilização dos métodos e mecanismos. Na literatura, considera-se que os projetos menos relevantes possam ser aprovados de maneira mais flexível (Arnold \& Hatzopoulos, 2000). O que a literatura não especifica são os critérios para que se entenda o que seriam esses projetos menos relevantes.

A quarta hipótese (projetos aprovados no planejamento estratégico são acompanhados de maneira mais estruturada do que os projetos aprovados no orçamento) foi confirmada $(\beta=0,43$, $p<0,01)$ para os projetos aprovados no planejamento estratégico e não significante para os projetos aprovados no orçamento, o que indica a importância do projeto aprovado no planejamento estratégico. De alguma maneira, os projetos realmente relevantes para a organização, sejam denominados ou não de estratégicos, são decididos a partir da formalização do planejamento estratégico e, posteriormente, merecem acompanhamento mais acurado. A literatura não trata a questão de o acompanhamento dos projetos decididos no planejamento estratégico serem distintos daqueles decididos no orçamento.

A quinta hipótese (maior necessidade de definição de financiamento e custo de oportunidade 
está associada positivamente à inclusão do projeto no planejamento estratégico) foi confirmada ( $\beta=$ $0,50, p<0,01)$, o que versa no sentido de que a necessidade de financiamento e de definição do custo de oportunidade estão associadas ao fato de o projeto ser analisado e decidido no planejamento estratégico. Essa associação é absolutamente racional, pois a sua ausência implica impossibilidade de aplicação dos métodos de avaliação de investimentos e, consequentemente, dos mecanismos. A sexta hipótese (maior horizonte de vida útil está associado positivamente à inclusão do projeto no planejamento estratégico) não foi confirmada. Logo, não se pode dizer que quanto mais longa a vida útil dos ativos incluídos no projeto maior a demanda para que sejam aprovados no planejamento estratégico.

A sétima hipótese (processos decisórios que envolvem conselho de administração são incluídos no planejamento estratégico) não foi confirmada. Não procede que quanto maior a dependência de aprovação do projeto de investimentos, por meio de seu conselho de administração, maior a possibilidade de que ele seja aprovado no planejamento estratégico.

A oitava hipótese (percepção de risco do projeto impacta a definição da decisão de aceitação do projeto ocorrer no planejamento estratégico ou no orçamento) também não foi confirmada. Portanto não é fato que a percepção do risco possa influenciar a decisão de aprovação do projeto ocorrer no planejamento estratégico ou no orçamento.

\section{Conclusões}

A escassez de informações acerca dos elementos que são considerados orientadores das decisões de investimentos pelas empresas brasileiras foi fator motivador deste estudo, que intencionou verificar se existe encaixe entre o modelo estruturado de análise de investimento proposto nas literaturas financeira e estratégica e as práticas dessa natureza adotadas por organizações brasileiras de grande porte. Trata-se de uma amostra de 82 empresas que exibem perfil relevante no que diz respeito aos investimentos de longo prazo no cenário nacional. Desse modo, mesmo sem possibilidade de generalização dos resultados, os achados desta pesquisa permitiram entender que existe aderência parcial ao referencial teórico nas ações das empresas brasileiras pesquisadas quando o assunto é investimento em ativos de longo prazo.

Tal afirmação está baseada em vários elementos, dentre os quais, destacam-se os métodos e mecanismos e as variáveis que indicam o relacionamento entre as decisões de investimentos na perspectiva empírica e seu constructo teórico.

Os métodos de avaliação de investimentos mais utilizados pelas empresas estudadas são aqueles apontados na literatura: valor presente líquido e taxa interna de retorno. Também em conformidade com a literatura, taxa de retorno modificada, payback simples, payback ajustado, índice de lucratividade e EVA foram indicados, nessa ordem, como mecanismos que fornecem suporte às decisões de investimentos de LP. Diferentemente do que se esperava, a frequência de utilização do payback simples foi superior à do payback ajustado. Esse achado indica que o horizonte de retorno parece estar sendo negligenciado pelas empresas estudadas para decisões de investimentos de LP. Quanto aos mecanismos auxiliares, as simulações foram apontadas como sendo o recurso mais recorrente para o tratamento de investimentos de LP no universo estudado. Verificou-se, ainda, que há alta correlação entre a utilização de métodos e mecanismos, o que não surpreende, pois não se podem desenvolver simulações sem que se disponha, por exemplo, de VPL, TIR, etc. Levantou-se que a escolha dos métodos é determinante da definição dos mecanismos, o que também faz sentido, visto que os mecanismos proporcionam um refinamento do produto gerado pelos métodos.

Constatou-se que os projetos implementados nas empresas estudadas são posteriormente acompanhados, o que fortalece a exploração de outros elementos ligados ao gerenciamento de investimentos de LP, tais como o ambiente em que é decidido e a mensuração da vida útil dos 
projetos. Quando se trata de aprovação de projetos, a figura do planejamento estratégico mostrou-se relevante no universo pesquisado, contudo o orçamento, ainda que de forma mais tímida, também foi indicado como um instrumento para aprovação dos projetos. A constatação de que alguns projetos não são aprovados por meio de um instrumento formal surpreendeu, assim, sugerindo que organizações que tenham investimentos relevantes no Brasil podem conviver com maior risco de retorno dos investimentos.

No que diz respeito ao financiamento dos investimentos, verificou-se que existe um descolamento entre as decisões de investimento e o financiamento dos projetos. Esse achado sinaliza uma fragilidade da ação estratégica das organizações pesquisadas, uma vez que, em alguns casos, o financiamento não tem representado objeto de preocupação quando da escolha por um projeto. De forma similar, a análise de risco, apesar de presente na gestão da maioria dos projetos, mostra-se limitada, uma vez que não tem sido desenvolvida individualmente, para cada projeto, limitando, dessa maneira, a análise realizada.

Assim, tem-se que a forma como o risco é percebido e valorizado nas organizações direciona a utilização de mecanismos. Complementarmente, ficou evidenciado que os projetos aprovados no planejamento estratégico sofrem acompanhamento mais estruturado do que aqueles cuja aprovação se dá no orçamento. Este achado reforça a importância do uso de mecanismos que proporcionem um refinamento do processo de acompanhamento dos projetos, permitindo a identificação de divergências entre o previsto e o realizado, bem como a recondução de eventual desvio às metas originais do projeto.

Os achados desta pesquisa sugerem que a utilização de ferramentas de gestão possa não estar sendo visualizada, pelas empresas pesquisadas, como um instrumento avaliativo de suas ações e capaz de suportar a identificação de um diferencial competitivo necessário à sua manutenção num horizonte de longo prazo.

Artigo recebido em 23.08.2010. Aprovado em 26.10.2011.

\section{Agradecimentos}

Os autores agradecem o apoio da FAPESP e CNPq ao projeto que originou este artigo, bem como a FIPECAFI que cedeu o banco de dados utilizado na pesquisa de campo.

\section{Nota}

${ }^{1}$ O presente trabalho corresponde a uma evolução de artigo apresentado no ENANPAD de 2010 (publicado como anais) e, posteriormente, apresentado no European Accounting Association Conference, de 2011 (este último publicado apenas sob a forma de abstract).

\section{Referências}

Alkaraan, F., \& Northcott, D. (2006). Strategic capital investment decision-making: a role for emergent analysis tools? A study of practice in large UK manufacturing companies. The British Accounting Review, 38(2), 149-173. doi: 10.1016/j.bar.2005.10.003 
Alkaraan, F., \& Northcott, D. (2007). Strategic investment decision making: the influence of predecision control mechanisms. Qualitative Research in Accounting \& Management, 4(2), 133150. doi: 10.1108/11766090710754204

Arnold, G. C., \& Hatzopoulos, P. D. (2000). The theory-practice gap in capital budgeting: evidence from the United Kingdom. Journal of Business Finance \& Accounting, 27(5-6), 603-626. doi: $10.1111 / 1468-5957.00327$

Banco Nacional de Desenvolvimento Econômico e Social. (2010). Circular $N^{o}$ 11/2010. Recuperado em $31 \quad$ maio, 2010, de http://www.bndes.gov.br/SiteBNDES/export/sites/default/bndes_pt/Galerias/Arquivos/produtos/ download/Circ011_10.pdf

Brigham, E. F., \& Ehrhardt, M. C. (2006). Financial management: theory and practice. São Paulo: Thomson Learning.

Butler, R., Davies, L., Pike, R. H., \& Sharp, J. (1991). Strategic investment decision-making: complexities, politics and processes. Journal of Management Studies, 28(4), 395-415. doi: 10.1111/j.1467-6486.1991.tb00288.x

Carr, C., \& Tomkins, C. (1998). Context, culture and the role of the finance function in strategic decisions. A comparative analysis of Britain, Germany, the U.S.A. and Japan. Management Accounting Research, 9(2), 213-239. doi: 10.1006/mare.1998.0075

Carr, C., Kolehmainen, K., \& Mitchell, F. (2010). Strategic investment decision making practices: a contextual approach. Management Accounting Research, 21(3), 167-184. doi: 10.1016/j.mar.2010.03.004

Cohen, J. R. (1977). Statistical power analysis for the behavioral sciences. New York: Academic Press.

Editora Abril. (2009). Revista Exame: melhores \& maiores. São Paulo, SP: autor.

Eisenhardt, K. M. (1989). Agency theory: an assessment and review. The Academy of Management Review, 14(1), 57-74. doi: 10.2307/258191

Fornell, C., \& Larcker, D. F. (1981). Evaluating structural equation models with unobservable variables and measurement error. Journal of Marketing Research, 18(1), 39-50. doi: $10.2307 / 3151312$

Gaver, J. J., \& Gaver, K. M. (1993). The association between performance plan adoption and corporate capital investment: a note. Journal of Management Accounting Research, 5(1), 145 158. doi: 10.1016/0165-4101(83)90003-4

Graham, J., \& Harvey, C. (2002). How do CFOs make capital budgeting and capital structure decisions? Journal of Applied Corporate Finance, 15(1), 8-23. doi: 10.1111/j.17456622.2002.tb00337.x

Hair, J. F., Jr., Anderson, R. E., Tatham, R. L., \& Black, W. C. (2005). Análise multivariada de dados (5a ed.). Porto Alegre: Bookman.

Haka, S. F. (2007). A review of the literature on capital budgeting and investment appraisal: past, present, and future musings. In C. S. Chapman, A. G. Hopwood, \& M. D. Shields (Eds.), Handbook of Management Accounting Research (Vol. 2, pp. 697-728). Oxford: Elsevier.

Henseler, J., Ringle, C. M., \& Sinkovics, R. R. (2009). The use of partial least squares path modeling in international marketing. Advances in International Marketing, 20, 277-319. doi: $10.1108 /$ S1474-7979(2009)0000020014 
Hirsch, P., Michaels, S., \& Friedman, R. (1987). "Dirty hands" versus "clean models": is sociology in danger of being seduced by economics? Theory and Society, 16(3), 317-336. doi: 10.1007/BF00139485

Ho, S. S. M., \& Pike, R. H. (1998). Organizational characteristics influencing the use of risk analysis in strategic capital investments. The Engineering Economist, 43(3), 247-268. doi: $10.1080 / 00137919808903198$

International Accounting Standards Board. (1989). Framework for the preparation and presentation of financial statements. Recuperado em 15 abril, de http://eifrs.iasb.org/eifrs/bnstandards/en/framework.pdf

Israel, R., \& Ma, Q. J. (1999). Investment horizon and the market for corporate control: the defensive role of long-term investments. Recuperado em 07 Julho, 2010, de http://ssrn.com/abstract=234874

Jarvis, C. B., MacKenzie, S. B., \& Podsakoff, P. M. (2003). A critical review of construct indicators and measurement model misspecification in marketing and consumer research. Journal of Consumer Research, 30(2), 199-218. doi: 10.1086/376806

Jensen, M. C., \& Meckling, W. H. (1976). Theory of the firm: managerial behavior, agency costs and ownership structure. Journal of Financial Economics, 3(4), 305-360. doi: 10.1016/0304$405 X(76) 90026-X$

Kim, S. H., \& Farragher, E. J. (1981). Current capital budgeting practices. Management Accounting, 62(12), 26-30.

Lambert, R. A. (2006). Agency theory and management accounting. Handbook of Management Accounting Research, 1(6), 247-268. doi: 10.1016/S1751-3243(06)01008-X

Lee, C. F. (1985). Financial analysis and planning: theory and application. Reading: Addison Wesley Longman.

Little, T. D., Lindenberger, U., \& Nesselroade, J. R. (1999). On selecting indicators for multivariate measurement and modeling with latent variables: When "good" indicators are bad and "bad" indicators are good. Psychological Methods, 4(2), 192-211. doi: 10.1037/1082-989X.4.2.192

Marsh, P., Barwise, P., Thomas, K., \& Wensley, R. (1988). Managing strategic investment decisions. In A. Pettigrew (Ed.), Competitiveness and the Management Process (pp. 86-136). Oxford: Basil Blackwell.

Mintzberg, H., Ahlstrand, B., \& Lampel, J. (1998). Safari da estratégia. Porto Alegre: Bookman.

Myers, S. C. (1984). The capital structure puzzle. The Journal of Finance, 39(3), 575-592. doi: $10.2307 / 2327916$

Pike, R. H. (1996). A longitudinal survey on capital budgeting practices. Journal of Business Finance \& Accounting, 23(1), 79-92. doi: 10.1111/j.1468-5957.1996.tb00403.x

Rappaport, A. (1998). Creating shareholder value (2a ed.). New York: Free Press.

Ringle, C. M., Wende, S., \& Will, S. (2005). SmartPLS (versão 2.0 M3 Beta) [Software]. Hamburg: SmartPLS.

Shapiro, A. C. (1998). Corporate strategy and the capital budgeting decision. In J. M. Stern \& D. H. Chew Jr. (Eds.), The Revolution in Corporate Finance (pp. 37-51). Malden: Blackwell. 
Shleifer, A., \& Vishny, R. W. (1986). Greenmail, white knights, and shareholders' interest. The Rand Journal of Economics, 17(3), 293-309.

Simons, R. (1995). Levers of control - how managers use innovative control systems to drive strategic renewal. Boston: Harvard Business School Press.

Slagmulder, R. (1997). Using management control systems to achieve alignment between strategic investment decisions and strategy. Management Accounting Research, 8(1), 103-139. doi: 10.1006/mare.1996.0035

Stein, J. C. (1988). Takeover threats and managerial myopia. Journal of Political Economy, 96(1), 6180. doi: $10.1086 / 261524$

Steiner, G. A. (1979). Strategic planning: what every manager must know. New York: Free Press.

Stewart, G. B. (1991). The quest of value. New York: Harper Business.

Subramaniam, N. (2006). Agency theory and accounting research: an overview of some conceptual and empirical issues. In Z. Hoque (Ed.), Methodological issues in accounting research: theories and methods (pp. 55-77). London: Spiramus.

Van Horne, J. C. (1995). Financial management and policy (10a ed.). Englewood Cliffs, NJ: Prentice Hall.

Verbeeten, F. H. M. (2006). Do organizations adopt sophisticated capital budgeting practices to deal with uncertainty in the investment decision? A research note. Management Accounting Research, 17(1), 106-120. doi: 10.1016/j.mar.2005.07.002

Welsch, G. A., Hilton, R. W., \& Gordon, P. N. (1988). Budgeting: profit planning and control (5a ed.). Englewood Cliffs, NJ: Prentice Hall. 